University of Windsor

Scholarship at UWindsor

2020

\title{
Two-echelon Supply Chain Operations under Dual Channels with Differentiated Productivities
}

\author{
Debing Ni \\ University of Electronic Science and Technology of China \\ Kevin Li \\ University of Windsor \\ Xiang Fang \\ University of Wisconsin-Milwaukee
}

Follow this and additional works at: https://scholar.uwindsor.ca/odettepub

Part of the Business Commons

\section{Recommended Citation}

$\mathrm{Ni}$, Debing; Li, Kevin; and Fang, Xiang. (2020). Two-echelon Supply Chain Operations under Dual Channels with Differentiated Productivities. International Transactions in Operational Research, 27 (2), 1013-1032. https://scholar.uwindsor.ca/odettepub/132

This Article is brought to you for free and open access by the Odette School of Business at Scholarship at UWindsor. It has been accepted for inclusion in Odette School of Business Publications by an authorized administrator of Scholarship at UWindsor. For more information, please contact scholarship@uwindsor.ca. 
International Transactions in Operational Research, 27(2): 1013-1032, 2020.

Two-echelon Supply Chain Operations under Dual Channels with Differentiated

\title{
Productivities
}

\author{
Debing $\mathrm{Ni}^{1}$, Kevin W. $\mathrm{Li}^{2}$, Xiang Fang ${ }^{3}$ \\ 1 School of Management and Economics, University of Electronic Science and Technology of China, \\ Chengdu, Sichuan, P. R. China, 611731. Email: nidb@uestc.edu.cn \\ 2 Odette School of Business, University of Windsor, Windsor, Ontario, Canada, N9B 3P4, \\ Email: kwli@uwindsor.ca \\ 3 Sheldon B. Lubar School of Business, University of Wisconsin-Milwaukee, Milwaukee, Wisconsin, \\ 53201-0742 Email: fangx@uwm.edu
}

Abstract: This paper examines a two-echelon supply chain with an upstream supplier (she) and a downstream manufacturer (he) transacting an intermediate product via direct bilateral contracting and futures market channels with differentiated productivities. A game model is established to examine the dual-channel supply chain operations. Analytical results reveal that downstream productivity improvement (DPI) through the bilateral interaction is necessary and sufficient for the supply chain members to trade in the bilateral channel in addition to the futures market. We show that, when the price in the futures market increases, the manufacturer would purchase less from the futures market and more from the supplier, which not only increases the supplier's expected profit but also increases her risk (variance of the profit) in equilibrium. Furthermore, we find that when the bilateral channel exhibits stronger DPI, the manufacturer obtains a higher expected profit and bears a higher risk, but the supplier enjoys a higher expected profit without incurring any additional risk.

Keywords: Supply chain relationship; Productivity improvement; Futures market; Contract; Game model 


\section{INTRODUCTION}

With the support of the internet, electronic marketplaces provide competitive secondary (spot) market channels for firms in a supply chain to trade their products. Such spot market channels may help mitigate the double-marginalization problem and, hence, improve supply chain efficiency. At the same time, firms trading in spot markets also bear a great deal of risks associated with volatile spot prices. However, futures markets, such as the Chicago Board of Trade (CBOT), the New York Mercantile Exchange (NYMEX) and the London Metal Exchange (LME), offer firms an alternative market channel to trade various commodities such as crude oil, metals, and plastics. Not only can futures markets enhance supply chain efficiency, but they can also be used to hedge against spot price risks.

Nowadays, the utilization of spot and/or futures markets is widely observed in practice. For example, HP's TradingHubs.com, a web-based secondary market, accommodated transactions of over \$45 million of parts and products from July 1999 to April 2000 (Lee and Whang, 2002). As for futures markets, Newman (2009) reports that, in the 2000s, an average of $30 \%-40 \%$ of the total trading activities for the coffee "C" contracts in the New York Board of Trade are made up by commercial traders who, unlike non-commercial traders such as hedgers and speculators conducting only financial trade, engage in physical commodity transactions with actual deliveries. Despite increasing popularity of e-markets, supply chain partners still use bilateral contracts for most transactions in the real business world. According to Electronics Business Network's 2002 poll of 150 original equipment manufacturers and their service providers, $72 \%$ of their procurement spending was executed through bilateral contracts and the same level was estimated for the coming year (Dong and Liu, 2007). 
47 Laughlin (2003) reports that $54 \%$ of the trading in the electric power market covered by PJM Interconnection was completed through bilateral transactions.

This co-existence of market trading and bilateral contracting arouses researchers in the field of supply chain and operations management to study why firms in a supply chain still transact by bilateral contracts in the presence of the more efficient market trading. They introduce spot market trading to supply chain models and furnish four different interpretations for the need of bilateral contracting to complement spot market trading: risk hedging (Dong and Liu, 2007), potential productivity improvement (Cohen and Agrawal, 1999; Levi et al., 2003), strategic threats under trigger strategies (Tunca and Zenios, 2006), and the price impact of buyers' strategic purchase in the spot market (Mendelson and Tunca, 2007). For more detailed survey on relationship between (spot) market trading and supply chain operations, readers are referred to Haksöz and Seshadri (2007) and Kleindorfer and $\mathrm{Wu}(2003)$.

However, little attention is paid to the impact of futures market trading on the negotiation of bilateral contracts in supply chains, although a few authors analyze optimization models where futures trading is assumed to hedge spot price risks (see, for example, Haksöz and Seshadri (2011)). Intuitively, if supply chain members trade in a futures market for actual deliveries, they can make commitments in terms of selling or buying a portion of intermediate products to strategically affect the following negotiation of their bilateral contracts. In this paper, we thus establish a three-stage game model to study the strategic role of committing to futures trading and to explore a new motivation for supply chain members to use the bilateral channel.

In this model, we consider a two-echelon supply chain consisting of an upstream supplier with 
uncertain unit production cost and a downstream manufacturer with stochastic final market demand. Both members have access to a futures market to trade an intermediate product. In addition to the futures trading channel, the transaction can also be completed by signing a bilateral wholesale price contract. Before negotiating the contract, the supplier (manufacturer) decides her (his) quantity to sell (buy) in the futures market at an observed futures price. After the bilateral contract is signed, the uncertain production cost for the supplier and the uncertain market demand for the manufacturer are realized, and both members fulfill their obligations set by the futures market and the wholesale price contract. Finally, the manufacturer sells the final product to consumers as per the realized demand.

In our model, we assume that the bilateral (contracting) channel improves the manufacturer's productivity compared with the futures market channel. This assumption is consistent with the general idea (as demonstrated in Cohen and Agrawal, 1999, Levi et al., 2003, Ulrich and Barney, 1984) that direct interactions through bilateral contracting rather than market trading help forge a better cooperation link, thereby improving productivities across the supply chain.

By analyzing the subgame perfect equilibrium of this game, we make a four-fold contribution to the literature. Firstly, we find that DPI is a necessary and sufficient condition for the supply chain to transact through bilateral contracting in the presence of the futures market, thereby establishing an alternative DPI interpretation for a positive bilateral transaction on top of Mendelson and Tunca's (2007) strategic price impact explanation and the strategic threats under trigger strategies in a repeated game setting in Taylor and Plambeck (2007a, 2007b). Secondly, it is shown that when DPI exists, ex ante commitment to futures market trading allows the equilibrium contract to be independent of the expected downstream market demand and upstream unit production cost. The implication of this 
independence result is that prior commitment to futures trading helps mitigate double marginalization. Thirdly, with a given DPI level, a higher futures price leads to a higher trading quantity at a heightened wholesale price in the bilateral channel, leading to a lower (higher) expected profit for the manufacturer (supplier) with a lower (higher) variance. This highlights that the futures price can serve as an indicator for supply chain managers to predict the change of bilateral contracting relations and the corresponding performance outcomes. This result is consistent with the price-to-be-fixed contracting practice in coffee supply chains where the contracted price is the futures price plus a quality adjustment (Bargawi and Newman, 2017; Starbucks, 2010) and Adcock’s (2006) appeal for (upstream) producers and (downstream) consumers to adopt the (LME) futures price as a benchmark for their (bilateral) price negotiations. Fourthly, for a given futures price, an increased DPI level strengthens the bilateral relation with a higher proportion of final product from the bilateral channel at an elevated wholesale price, and the result yields a win-win performance scenario, in which both the supplier and the manufacturer achieve a higher expected profit with different risk implications. This result furnishes a plausible way to understand the asymmetric reliance on relationship-based collaborations and different motivations for these collaborations observed in the B2B relationship management literature (Collins and Burt, 1999; Allen, 2001; Hingley, 2005; Nyaga et al., 2010).

The remainder of this paper is organized as follows. We briefly review related literature in Section 2. Section 3 presents a three-stage game model to describe our supply chain setting. The corresponding subgame perfect equilibrium is derived in Section 4. Section 5 reports how the futures price and DPI affect supply chain operations and the corresponding implications on profitability and the associated risk. Concluding remarks are summarized in Section 6. All mathematical proofs are provided in 


\section{LITERATURE REVIEW}

Motivated by the electronic marketplace TradingHubs.com, Lee and Whang (2002) triggers an

114 interest to study how competitive market trading complements bilateral contract transactions in supply

115 chains. A central question is why supply chain members still transact by bilateral contracts given that

116 more efficient markets are available to buy or sell intermediate products. Dong and Liu (2007) view a

117 bilateral contract as a forward contract between a supplier and a manufacturer in a supply chain and

118 establish that the risk-hedging benefit justifies the prevalent existence of bilateral contracting within

119 supply chains in the presence of open market trading. Mendelson and Tunca (2007) demonstrate that

120 spot market trading improves supply chain channel profit and consumer surplus. However, due to the

121 strategic impact on the equilibrium price of the spot market, it does not eliminate bilateral fixed-price

122 contracting even if these contracts are signed under inferior information.

123 Another line of research adopts the concept of the so-called relational contract to understand

124 long-term collaborations among supply chain members. Tunca and Zenios (2006) model an e-market

125 clearing mechanism between multiple suppliers and a set of manufacturers as a price-based auction

126 and reveals conditions for these two venues to coexist and conditions under which one is preferred to

127 the other. The authors point out that the auction-based market trading does not necessarily increase

128 supply chain channel profit or consumer surplus. Without considering market trading, Taylor and

129 Plambeck (2007a) provide two types of simple relational contracts (i.e. price-only and

130 price-and-quantity contracts) and compare their optimal performance from the buyer's perspective. 
131 From the viewpoint of a supply chain system, Taylor and Plambeck (2007b) derive a general optimal

132 relational contract that specifies a lump-sum transfer and a quantity-contingent payment from the

133 buyer to the seller, a demand-dependent order, and the seller's capacity investment. They show with

134 two simpler versions of relational contracts (i.e. no-monitoring and capacity- inspection contracts) that

135 both contracts perform well for a broad range of parameters.

136 A different body of literature explores some "physical" aspects of bilateral contracting relations in

137 supply chains. Cohen and Agrawal (1999) study a buyer's trade-off between short-term (spot trading)

138 and long-term contracts, where the latter possesses productivity improvement opportunities. The

139 contracting market model of Levi et al. (2003) indicates that low relationship-specific investment leads

140 to extensive use of contract trading. Both Cohen and Agrawal (1999) and Levi et al. (2003) recognize

141 that long-term contracting requires some specific investment, which in turn leads to operational cost

142 savings at one or more firms in a supply chain. This cost saving may take different forms such as

143 rekeying cost and clerical expenses under EDI (Dearing, 1990), monitoring costs due to a reduction of

144 opportunistic behavior by reducing the investor's bargaining power (Ulrich and Barney, 1984), and

145 maintenance and smoothing costs (Levi et al., 2003). Cost savings via bilateral contracting can be

146 interpreted as increased production efficiency or productivity.

147 Our paper has the following major differences from the aforementioned literature. Firstly, our

148 model is different from the problem considered by Cohen and Agrawal (1999) as their research is

149 essentially an optimization model from the buyer's perspective. Secondly, our exposition differs from

150 that reported by Levi et al. (2003) as they investigate how the contracting market equilibrium is

151 reached with competitive contract offers. Thirdly, our main concern here is how supply chain 
152 operations are affected by potential productivity improvement resulted from bilateral contracting

153 instead of strategic threats under trigger strategies (Taylor and Plambeck, 2007a; 2007b). Fourthly,

154 Dong and Liu (2007) reveal the risk hedging motivation of bilateral contracting. We focus on the

155 strategic role of futures market trading in the bilateral contract negotiation. Finally, but more

156 importantly, the endogenously determined spot price in equilibrium in Mendelson and Tunca (2007)

157 validates the price impact of strategic spot market trading on fixed-price contracting and a high enough

158 level of the price impact leads to a positive contract transaction. In contrast, the model here assumes

159 that supply chain members are engaged in futures trading and the quantities herein do not have any

160 (futures) price impact on bilateral contract negotiation. This makes downstream productivity

161 improvement (DPI) a potential factor for explaining a positive contracting transaction

\section{3. THE MODEL}

163 Consider a two-echelon supply chain consisting of an upstream supplier and a downstream

164 manufacturer. The two members use a wholesale price contract to trade an intermediate product. The

165 manufacturer may also purchase the intermediate product from the futures market, and the supplier

166 may also sell her intermediate product via the futures market. The manufacturer uses the intermediate

167 product to produce his final product with an uncertain market demand. The market price of the

168 manufacturer's final product, defined as $p$, is characterized by an inverse demand function

169

$$
p=a+\varepsilon-b Q_{m}
$$

170 where $\varepsilon \sim N\left(0, \sigma_{\varepsilon}^{2}\right)$ representing market uncertainty, and $Q_{m}$ is the total output quantity of the 171 manufacturer's final product demanded in the final market.

172 Since the manufacturer procures the intermediate product from two different channels, i.e., the 
173 bilateral contract with the supplier and the futures market. We use $q_{s}$ to denote the manufacturer's

174 procurement quantity from the supplier and $q_{m f}$ to represent the manufacturer's procurement

175 quantity from the future market, respectively. Additionally, we assume that bilateral contracting

176 facilitates downstream productivity improvement (DPI). Therefore, the total output quantity of the 177 manufacturer's final product, $Q_{m}$, can be described as

$$
Q_{m}=k q_{s}+q_{m f}
$$

179 where $k \geq 1$ measures the manufacturer's relative productivity improvement for the procured 180 intermediate products from the bilateral contracting channel compared to those obtained from the 181 futures market. When $k=1$, bilateral contracting does not have any productivity enhancement for the 182 manufacturer and a higher $k$ indicates a higher improvement level. The productivity improvement in 183 bilateral contracting is usually attributed to long-term relationship-specific investment that has been 184 made through repeated transactions in the past and is often assumed sunk. For instance, Cohen and 185 Agrawal (1999) and Levi et al. (2003) treat this cost saving as an exogenous and, thus, sunk, prior to 186 contract negotiation.

187 Dong and Liu (2007) have identified the risk-hedging benefits for bilateral contracts against the 188 volatile spot market. In this paper, we aim to show that DPI alone induces bilateral contracts. To 189 exclude spot price risks, we assume that the supplier (manufacturer) obtains a fixed unit revenue (cost), 190 i.e., $F(<a)$ in the futures market channel. Note that in our model, we assume that the supplier sells 191 and the manufacturer buys at the same futures price. In reality, the manufacturer and the supplier may 192 trade in the futures market at different physical time points and, thus, at different futures prices. To 193 cope with this, without loss of generality, we assume that the supplier sells at $F+\Delta F$ while the 
manufacturer buys at $F$, where $\Delta F$ can be positive or negative. Under this alternative assumption, we can still prove that the game has a unique subgame perfect equilibrium and derive it in a closed form. Furthermore, we can show that there exists a threshold, $\overline{\Delta F}$, such that for all $\Delta F \in(-\overline{\Delta F}, \overline{\Delta F})$, all the managerial implications (in Section 5) still hold. For more details, please refer to Appendix B.

Let $w$ be the unit wholesale price charged by the supplier to the manufacturer for the intermediate product. Thus, the manufacturer's profit function can be written as

$$
\pi_{m}=\left[a+\varepsilon-b\left(k q_{s}+q_{m f}\right)\right]\left(k q_{s}+q_{m f}\right)-w q_{s}-F q_{m f}
$$

As in Dong and Liu (2007), we assume that both the supplier and the manufacturer are risk-averse and have mean-variance preference over their risky profits. Risk-averse decision-makers are empirically observed in the literature (e.g. Cramer et al., 2002; Willebrands et al., 2012; Cucculelli and Ermini, 2013), and, as suggested by Kirkwood's (2004) simulation results, an exponential utility function is an appropriate choice to represent risk-averse decision-makers' preferences. In theory, a mean-variance preference can be justified by the certainty equivalence of the expected utility with an exponential utility function and a normally distributed uncertainty (Mascell et al. 1995). Therefore, we use certainty equivalence as the objective functions for both the manufacturer and the supplier. More specifically, we below assume both firms have exponential utility functions with Arrow-Pratt absolute risk measures of $\rho_{s}$ and $\rho_{m}$ (where subscripts "s" and "m" represent the supplier and the manufacturer, respectively) and the uncertainties of the manufacturer's demand and the supplier's cost follow normal distributions.

With the normality assumption of $\varepsilon$, the exponential utility function and a large enough $a$ (for instance, $a>3 \sigma_{\varepsilon}$, such that $p$ and $\pi_{m}$ are negative with negligible probabilities), the manufacturer's 
certainty equivalence is expressed as

$216 C V_{m}=E \pi_{m}-\frac{1}{2} \rho_{m} \operatorname{var} \pi_{m}=\left[a-b\left(k q_{s}+q_{m f}\right)\right]\left(k q_{s}+q_{m f}\right)-w q_{s}-F q_{m f}-\frac{1}{2} \rho_{m} \sigma_{\varepsilon}^{2}\left(k q_{s}+q_{m f}\right)^{2}$

Assume that the supplier has a sufficiently large capacity and her unit production cost $c$ is 218 stochastic and $c \sim N\left(c_{0}, \sigma_{c}^{2}\right)$ where $0<c_{0}<F$ and $\sigma_{c}^{2}$ is sufficiently small relative to $219 F-c_{0}$ (for example, $3 \sigma_{c}<F-c_{0}$ ). The assumption of random unit cost for the supplier reflects the uncertainty in her procurement process of raw materials. The supplier can sell her intermediate product to the manufacturer directly or to the futures market. Hence, the supplier's profit function is

$$
\pi_{s}=w q_{s}+F q_{s f}-c\left(q_{s}+q_{s f}\right)
$$
where $q_{s}$ and $q_{s f}$ are the quantities that the supplier sells to the manufacturer at the unit wholesale 224 price $w$ and to the futures market at unit price $F$, respectively. The corresponding certainty equivalence is

In our model, the decision sequence is as follows. In stage 0 , based on an observed futures price $F$, 228 the manufacturer and the supplier choose $q_{m f}$ and $q_{s f}$ simultaneously. Then the supplier decides $w$ 229 in stage 1 . In stage 2, the manufacturer determines $q_{s}$ as per the wholesale price $w$ selected by the 230 supplier. Finally, the supplier's unit cost $c$ is realized, the supplier produces $q_{s}+q_{s f}$, and the 231 manufacturer receives $q_{s}+q_{m f}$ from the supplier and the futures market. The final market 232 uncertainty $\varepsilon$ is realized and the manufacturer sells his full production $k q_{s}+q_{m f}$ in the final market 233 at the market-clearing price according to the inverse demand function (1).

234 The futures market makes it possible for the supplier and the manufacturer to engage in market 
235 trading prior to negotiating their bilateral contract. The decision sequence that $q_{m f}$ and $q_{s f}$ are 236 chosen prior to determining $w$ and $q_{s}$ in the bilateral contract allows us to examine the impact of 237 futures commitments on bilateral contract relations and supply chain operations.

238 Finally, all mathematical notations are listed in Table 1.

\begin{tabular}{ll}
\hline Symbol & Description \\
\hline$\rho_{s}, \rho_{m}$ & The supplier's and the manufacturer's Arrow-Pratt absolute risk measure \\
$\varepsilon$ & The normally distributed random shock of the final market demand with an expected value of zero \\
$\sigma_{\varepsilon}^{2}$ & The variance of the random shock of the final market demand \\
$a, b$ & The market size and the slope of the (expected) final market demand \\
$p, Q_{m}$ & The market-clearing price and the total output quantity of the manufacturer's product in the final \\
& market \\
$c_{0}, \sigma_{c}^{2}$ & The normally distributed random unit cost of the supplier \\
$k$ & The expected value and variance of the supplier's random unit cost \\
$q_{s}$ & The parameter indicating the downstream productivity improvement (DPI) \\
$w$ & The supplier's unit wholesale price for the intermediate product sold to the manufacturer \\
$q_{s f}, q_{m f}$ & The supplier's and the manufacturer's respective quantity traded in the futures market \\
$F$ & The futures price for the intermediate product \\
$\pi_{s}, \pi_{m}$ & The supplier's and the manufacturer's profit \\
$C V_{s}, C V_{m}$ & The supplier's and the manufacturer's certainty equivalence \\
\hline
\end{tabular}

\section{THE EQUILIBRIUM}

As specified in the sequence of events in Section 3, our model is a three-stage game including stages 0,1 , and 2. Following backward induction, we solve the last stage first. In stage 2, the

244 manufacturer chooses $q_{s}$ to maximize $C V_{m}$ given in (3). Since it is straightforward to show $C V_{m}$

245 is concave in $q_{s}$, the first-order condition immediately implies that the manufacturer's optimal 246 response (in terms of an optimal order quantity) can be characterized in Lemma 1. For notational 
247 convenience, let $B \stackrel{\text { def }}{=} 2 b+\rho_{m} \sigma_{\varepsilon}^{2}$.

248 Lemma 1: In stage 2, given $q_{m f}, q_{s f}$, and $w$, the manufacturer's optimal order quantity from the 249 supplier is wholesale price) can be given in Lemma 2. For notational convenience, let $A \stackrel{\text { def }}{=} \rho_{s} \sigma_{c}^{2}$.

255 Lemma 2: In stage 1, given $q_{m f}$ and $q_{s f}$, anticipating the manufacturer's optimal response (5), the supplier's optimal wholesale price is

$$
w=\frac{\left(k+\frac{A}{k B}\right) a-\left(k B+\frac{A}{k}\right) q_{m f}+c_{0}+A q_{s f}}{2+\frac{A}{k^{2} B}}
$$

Lemma 2 indicates that the wholesale price decreases in $q_{m f}$ but increases in $q_{s f}$. That is, if the manufacturer strategically purchases more of the intermediate product from the futures market, the supplier has to lower her unit wholesale price charged to the manufacturer, benefiting the manufacturer; on the other hand, if the supplier strategically sells more in the futures market, the supplier can charge a

262 higher unit wholesale price in the bilateral channel, resulting in a benefit for the supplier. Therefore, 263 both the manufacturer and the supplier have incentives to trade in the futures market prior to their 264 contract negotiation, and their commitments to a higher quantity in the futures market trading will 265 enhance their respective positions in the wholesale price contract negotiation. 
Now, we turn to stage 0 of our model, in which the manufacturer and the supplier play a 267 simultaneous-move game by selecting $q_{m f}$ and $q_{s f}$, respectively. With (5) and (6), the 268 manufacturer's and the supplier's certainty equivalence can be rewritten as $269 C V_{m}\left(q_{m f}, q_{s}\left(w\left(q_{m f}, q_{s f}\right)\right), w\left(q_{m f}, q_{s f}\right)\right)$ and $C V_{s}\left(q_{s f}, q_{s}\left(w\left(q_{m f}, q_{s f}\right)\right), w\left(q_{m f}, q_{s f}\right)\right)$, respectively. One 270 can directly verify that $C V_{m}$ is concave in $q_{m f}$ and $C V_{s}$ is concave in $q_{s f}$. Then it is sufficient to 271 use the first-order conditions to characterize the stage-0 interaction.

272 The first-order condition for the manufacturer is

$$
\begin{aligned}
\frac{\mathrm{d} C V_{m}}{\mathrm{~d} q_{m f}} & =\left(\frac{\partial C V_{m}}{\partial q_{s}} \frac{\partial q_{s}}{\partial w}+\frac{\partial C V_{m}}{\partial w}\right) \frac{\partial w}{\partial q_{m f}}+\frac{\partial C V_{m}}{\partial q_{m f}} \\
& =\left[\frac{w\left(q_{m f}, q_{s f}\right)}{k}-q_{s}\left(w\left(q_{m f}, q_{s f}\right)\right) \frac{\partial w}{\partial q_{m f}}\right]-F \\
& =\frac{\left(k^{2} B+A\right)\left(3 k^{2} B+A\right) a-B\left(k^{2} B+A\right)\left(3 k^{2} B+A\right) q_{m f}+k^{3} B^{2} c_{0}+k^{3} B^{2} A q_{s f}}{\left(2 k^{2} B+A\right)^{2}}-F \\
& =0
\end{aligned}
$$

274 where the second equality holds since the manufacturer's first-order condition $\partial C V_{m} / \partial q_{s}=0$ holds 275 (or equivalently (5) holds).

276 In (7), $F$ is the manufacturer's cost of buying an extra unit of the intermediate product in the 277 futures market while the bracketed terms represent a cost saving in the purchase in the bilateral channel. 278 Thus the manufacturer's optimal decision of his futures market trading quantity is determined by a 279 trade-off between these two terms. By solving the manufacturer's first-order condition, we obtain 280 Lemma 3.

281 Lemma 3: Anticipating the optimal responses (5) and (6), for any $q_{\text {sf }}$ chosen by the supplier, the 282 manufacturer's optimal order quantity from the futures market in stage 0 is 


$$
q_{m f}=\frac{k^{3} B A q_{s f}}{\left(k^{2} B+A\right)\left(3 k^{2} B+A\right)}+\frac{a}{B}+\frac{k^{3} B c_{0}}{\left(k^{2} B+A\right)\left(3 k^{2} B+A\right)}-\frac{\left(2 k^{2} B+A\right)^{2} F}{B\left(k^{2} B+A\right)\left(3 k^{2} B+A\right)} .
$$

Lemma 3 directly implies that $q_{m f}$ decreases in $F$. Intuitively, when the price of the intermediate product in the futures market $(F)$ increases, the manufacturer tends to order less from the futures market.

Similarly, the supplier's first-order condition in stage 0 is

$$
\begin{aligned}
\frac{\mathrm{d} C V_{s}}{\mathrm{~d} q_{s f}} & =F-\left[c_{0}+A\left(q_{s}\left(w\left(q_{m f}, q_{s f}\right)\right)+q_{s f}\right)\right] \\
& =F-\frac{2 k^{2} B c_{0}+k A a-k B A q_{m f}+2 k^{2} B A q_{s f}}{2 k^{2} B+A} \\
& =0
\end{aligned}
$$

In (10), $F$ is the supplier's revenue of selling an extra unit of the intermediate product in the futures market while the bracketed terms represent the supplier's increased cost of producing the extra unit. Thus, the supplier's optimal sales quantity to the futures market is induced by a trade-off between her marginal revenue and marginal cost of producing an extra unit. Based on the supplier's first-order condition, we reach Lemma 4.

294 Lemma 4: Anticipating the optimal responses (5) and (6), for any $q_{m f}$ chosen by the manufacturer, the supplier's optimal quantity sold to the futures market in stage 0 is

Lemma 4 indicates that $q_{s f}$ increases in $F$. Intuitively, when the price of the intermediate product in the futures market $(F)$ increases, the supplier would like to sell more to the futures market.

$$
q_{s f}=\frac{q_{m f}}{2 k}-\frac{a}{2 k B}-\frac{c_{0}}{A}+\frac{\left(2 k^{2} B+A\right) F}{2 k^{2} B A}
$$
only sells her intermediate product to the futures market but never purchases from it and the 
manufacturer only procures his input from the futures market but never sells to it. These conditions imply that the supplier and the manufacturer are "real" business entities (or commercial traders) that produce and deliver physical goods and do not participate as arbitrageurs in the futures market.

With Lemmas $1-4$, we are now ready to present the subgame perfect equilibrium by solving (9) and (12) for non-negative $q_{m f}^{*}$ and $q_{s f}^{*}$, which are subsequently plugged into (5) and (6) to solve for

$306 w^{*}$ and $q_{s}^{*}$. These results are summarized in Proposition 1.

Proposition 1: Keeping other parameters constant, there exist thresholds $B^{\#}$ and $a^{\#}(B)$ for each $B\left(\geq B^{\#}\right)$ such that if $B \geq B^{\#}$ and $a \geq a^{\#}(B)$, our three-stage game has a unique subgame perfect equilibrium as follows:

$$
\begin{gathered}
q_{m f}^{*}=\frac{a-F}{B}+\frac{k(1-k) F}{3 k^{2} B+2 A}, q_{s f}^{*}=\frac{F-c_{0}}{A}-\frac{(k-1)\left(2 k^{2} B+A\right) F}{k^{2} B\left(3 k^{2} B+2 A\right)} \\
w^{*}=\frac{\left[k^{2} B(1+2 k)+A(1+k)\right] F}{3 k^{2} B+2 A}, q_{s}^{*}=\frac{(k-1)\left(2 k^{2} B+A\right) F}{k^{2} B\left(3 k^{2} B+2 A\right)},
\end{gathered}
$$

where all these decisions in equilibrium are non-negative.

The threshold conditions in Proposition 1 simply ensure that neither the supplier nor the manufacturer is a hedger or a speculator who just uses the futures market trading as a financial instrument, instead, they are commercial traders who settle the futures contract with actual delivery. With the definition of $B=2 b+\rho_{m} \sigma_{\varepsilon}^{2}$, the condition $B \geq B^{\#}$ represents a non-trivial operational scenario where the final market demand is inelastic enough, the manufacturer is risk-averse enough, or the final market is risky enough. The condition $a \geq a^{\#}(B)$ simply means that the expected market size is large enough. For the remainder of this paper, we assume that these two conditions are satisfied. Proposition 1 indicates that the wholesale price $\left(w^{*}\right)$ and the supplier's selling quantity to the 
321 manufacturer $\left(q_{s}^{*}\right)$ in equilibrium are independent of the manufacturer's expected market demand $(a)$ 322 and the supplier's expected unit production cost $\left(c_{0}\right)$. However, if there does not exist the futures 323 market trading channel for the intermediate product, it is straightforward to show that the equilibrium 324 wholesale price increases in both $a$ and $c_{0}$, whereas the equilibrium trading quantity between the 325 manufacturer and the supplier increases in $a$ but decreases in $c_{0}$. When the futures market trading 326 channel exists, based on an observed futures price, the ex ante (stage-0) committed trading in the 327 futures market eliminates the impact of the expected downstream market demand and upstream 328 production cost on the ex post (stage-1 and stage-2) bilateral contract relation between the 329 manufacturer and the supplier.

330 This independence result can be explained by examining the manufacturer's and the supplier's 331 behavioral motivations in a more detailed fashion. For an increase of $\Delta a$ in $a$, as both the 332 manufacturer's and the supplier's reaction curves shift upwards to the same degree $(\Delta a / B)$, the 333 manufacturer's purchase in the futures market increases by $\Delta q_{m f}=\Delta a / B$ with a constant supplier's 334 sales to the futures market. These ex ante strategic commitments to the futures market trading of the 335 manufacturer and the supplier lead to an unchanged ex post bilateral transaction between them. When 336 the expected final market demand increases by $\Delta a$ and the manufacturer increases its futures market 337 purchase by $\Delta q_{m f}=\Delta a / B$, the manufacturer's order quantity from the supplier remains the same for 338 any wholesale price $w\left(\Delta q_{s}(w) / \Delta a=0\right.$ from (5)). This further eliminates the supplier's motivation 339 to raise the wholesale price ( $\Delta w / \Delta a=0$ from (6)). Thus, the trading quantity and wholesale price in 340 the bilateral channel are independent of $a$. Given this unchanged bilateral contract transaction, the 341 supplier's marginal cost of producing an extra unit for selling in the futures market will not be affected 
342 by $a$. Thus, the supplier has no incentive to change her futures market sales, resulting in no impact on

343 the contract negotiation (cf. (6)). In a similar way, one can explain why the equilibrium wholesale price 344 contract is independent of the supplier's expected cost $\left(c_{0}\right)$. A higher $c_{0}$ reduces the supplier's $e x$ 345 ante commitment to futures market trading quantity and this lower futures market sales buffers the 346 supplier's ex post motivation to raise the wholesale price (cf. (6)) in the bilateral contract negotiation 347 stage, leading to a constant wholesale price. The unchanged wholesale price subsequently leaves the 348 supplier with the same sales quantity in the bilateral channel.

349 The independence result suggests that ex ante commitments to futures market trading of supply 350 chain members automatically suppress their opportunistic tendency to modify the ex post wholesale 351 contract relative to any change in the supplier's expected production cost and/or the manufacturer's 352 expected final market demand. Note that each of these two factors influences the supplier's wholesale 353 price marginalization in a standard wholesale price contract setting. In contrast, in our current model 354 setting, the price marginalization is immune to any change in the supplier's expected production cost 355 and/or the manufacturer's expected final market demand. Thus, the independence result indicates that 356 prior commitments to futures trading help mitigate double marginalization between the two supply 357 chain members.

358 Furthermore, one can verify that $w^{*} \in(F, k F)$ for all $k>1$. The inherent rationale is that both 359 parties' ex ante commitment to futures market trading results in an equilibrium wholesale price that 360 allows both parties to trade via the bilateral channel: $w^{*}>F$ implies that the supplier is willing to sell 361 to the manufacturer and $w^{*}<k F$ gives the manufacturer a motivation to buy from the supplier. 362 Together with the mitigation of double marginalization, the use of the bilateral channel with higher 
363 productivity shall presumably lead to a higher operational efficiency for the supply chain. The

364 allocation of such efficiency gains depends on the futures price $(F)$ and the level of productivity 365 improvement $(k)$.

366 Corollary 1: If $k=1$, the subgame perfect equilibrium reduces to $q_{m f}^{*}=(a-F) / B$, $367 \quad q_{s f}^{*}=\left(F-c_{0}\right) / A, w^{*}=F$ and $q_{s}^{*}=0$.

368 Corollary 1 shows that the futures market trading channel for the intermediate product completely 369 overrides bilateral channel if $k=1$. In this case, the equilibrium trading quantity in the bilateral 370 channel $\left(q_{s}^{*}\right)$ becomes zero. Recall that $k=1$ means that there is no relative DPI for the manufacturer 371 based on his bilateral interactions with the supplier. Therefore, Proposition 1 and Corollary 1 jointly 372 indicate that the existence of DPI, i.e., $k>1$, is a necessary and sufficient condition for the bilateral 373 contracting to arise as a viable channel in the supply chain and DPI can be viewed as an effective 374 indicator for explaining when a positive bilateral transaction arises in the presence of dual channels in 375 the supply chain.

\section{5. MANAGERIAL IMPLICATIONS}

377 In this section, we derive managerial insights based on comparative statics with regard to the futures 378 price and DPI in a one-at-a-time manner. When there is no DPI in the bilateral channel (i.e., $k=1$ ), 379 the supplier and the manufacturer would stop using the bilateral channel to trade the intermediate 380 product in equilibrium (i.e., $\left.q_{s}^{*}=0\right)$ and the comparative statics in this case becomes trivial. Therefore, 381 we will focus on the interesting case $k>1$ in this section.

\section{$382 \quad 5.1$ Impact of the Futures Price}

383 We first consider the impact of the futures price on supply chain operations in equilibrium. 
384 Proposition 2: If the futures price $(F)$ increases, then for all $k>1$, the equilibrium wholesale price $385\left(w^{*}\right)$ and the equilibrium quantity $\left(q_{s f}^{*}\right)$ that the supplier sells to the futures market increase, but the equilibrium quantity $\left(q_{s}^{*}\right)$ that the supplier sells to the manufacturer and the equilibrium quantity $\left(q_{m f}^{*}\right)$ that the manufacturer purchases from the futures market decrease.

Proposition 2 is generally consistent with our conventional wisdom. That is, when the futures price $(F)$ of the intermediate product increases, the supplier would like to sell more to the futures market (i.e., $q_{s f}^{*}$ increases), and the manufacturer tends to purchase less from the futures market (i.e., $391 q_{m f}^{*}$ decreases). Facing a higher unit revenue $(F)$ from the futures market, the supplier has stronger motivation to raise her wholesale price $\left(w^{*}\right)$ charged to the manufacturer, which induces the manufacturer to order less from the supplier (i.e., $q_{s}^{*}$ decreases). Our result is aligned with the price-to-be-fixed contract used in transacting coffee of bulk grades between international traders and 395 Tanzanian exporters. The contracted price in this bilateral channel equals to the futures price of the 396 coffee at a particular point in time, plus or minus an agreed differential for quality difference (Bargawi 397 and Newman, 2017). Moreover, a trader in this coffee supply chain, interviewed by Bargawi and 398 Newman, acknowledged that "the futures price is the determinant all along the chain." Similar 399 price-to-be-fixed contract is also adopted by Starbucks (Starbucks 2010). Underpinned by the practices 400 in coffee supply chains, Proposition 2 provides a theoretical support for Adcock's (2006) appeal that 401 the futures prices in the London Metal Exchange (LME) is ready to be used as benchmarks for both 402 (upstream) producers and (downstream) consumers in their bilateral contract negotiations. The next proposition illustrates the impact of the futures price on the equilibrium performance of 404 the supply chain members whose expected profits and variances are as follows: 


$$
E \pi_{s}^{*}=w^{*} q_{s}^{*}+F q_{s f}^{*}-c_{0}\left(q_{s}^{*}+q_{s f}^{*}\right), \operatorname{var} \pi_{s}^{*}=\sigma_{c}^{2}\left(q_{s}^{*}+q_{s f}^{*}\right)^{2} .
$$

407 Proposition 3: If the futures price $(F)$ increases, then for all $k>1$, the manufacturer's expected 408 profit $\left(E \pi_{m}^{*}\right)$ and the corresponding variance ( $\operatorname{var} \pi_{m}^{*}$ ) of his profit in equilibrium decrease, but for 409 the supplier, her expected profit $\left(E \pi_{s}^{*}\right)$ and the variance ( $\left.\operatorname{var} \pi_{s}^{*}\right)$ of her profit in equilibrium increase. Proposition 3 shows that an increase in the futures price leads to a decrease in the manufacturer's 411 expected profit and risk (as captured by the variance), but it increases the supplier's expected profit and 412 risk. Intuitively, when the futures price increases, the manufacturer's opportunity cost (buying in the 413 futures market) increases, so the supplier would take advantage of this chance to charge the 414 manufacturer a higher wholesale price. Therefore, an increased futures price drives the manufacturer's 415 procurement costs higher in both channels, thereby reducing his order quantities in the two channels. 416 Thus, the manufacturer would have a lower profit and a lower risk. In contrast, an increase in the 417 futures price leads to higher marginal revenues for the supplier in both channels which stimulates the 418 supplier to expand her production, resulting in a higher profit with a higher risk. This suggests that in 419 terms of expected profits, a change in the futures price does not induce a win-win situation for both 420 supply chain members. Such asymmetric impacts on supply chain members' profitability shed some 421 light on supply chain relationship management: although the competitive futures market trading helps 422 improve supply chain efficiency, it also brings possibilities for one supply chain member to take 423 advantage of the other in negotiating the bilateral contract. A practical response to this issue is that 424 about $2 / 3$ of US companies have implicit contracts for prices or implicit understanding with their 425 customers to guard against such opportunistic behaviors in the presence of volatile prices (Grey et al., 


\subsection{Impact of Downstream Productivity Improvement}

428 Now, we consider the impact of DPI on supply chain operations. For ease of discussion, we define, $429 Q_{m}^{*}=k q_{s}^{*}+q_{m f}^{*}$ and $Q_{s}^{*}=q_{s}^{*}+q_{s f}^{*}$ to represent the total equilibrium output volume of the 430 manufacturer and the supplier, respectively. Then we have the following proposition.

431 Proposition 4: If DPI $(k)$ increases, then (i) the equilibrium quantity $\left(q_{m f}^{*}\right)$ that the manufacturer 432 purchases from the futures market decreases; (ii) the equilibrium wholesale price ( $\left.w^{*}\right)$ increases; (iii) 433 the manufacturer's equilibrium total output volume $\left(Q_{m}^{*}\right)$ increases, and (iv) the supplier's equilibrium 434 total output volume $\left(Q_{s}^{*}\right)$ remains unchanged.

Proposition 4 indicates that when the manufacturer enjoys a higher DPI from the bilateral channel, he becomes less dependent on the futures market, so he has a tendency to purchase less from the

437 futures market. When the manufacturer becomes more dependent on the bilateral channel, the supplier 438 can use it as a leverage to charge a higher wholesale price for each unit sold to the manufacturer. Due 439 to the higher productivity improvement from the bilateral channel, the manufacturer's total output 440 volume is expected to increase. However, the supplier would keep her total output volume unchanged.

441 Such asymmetric reliance of supply chain members on relationship-based productivity improvements 442 are empirically observed in the B2B relationship management literature (Hingley, 2005; Nyaga et al., 443 2010). When the manufacturer shifts more of his production of the final product from the futures 444 market to the bilateral channel, it makes his demand for the intermediate product from the bilateral 445 channel less elastic: for any change in the wholesale price set by the supplier, the change in the 446 manufacturer's order quantity becomes smaller. This reduced elasticity then enables the supplier to 
447 benefit from a higher wholesale price rather than from production expansion. Therefore, it is best for 448 the supplier to charge a higher wholesale price but keep her total production volume unchanged.

449 Proposition 5 below summarizes how the performances of the manufacturer and the supplier 450 respond to a change in DPI.

451 Proposition 5: If DPI ( $k$ ) increases, then the manufacturer's expected profit (E$\left.\pi_{m}^{*}\right)$ and the 452 corresponding variance ( $\operatorname{var} \pi_{m}^{*}$ ) of his profit in equilibrium increase, but for the supplier, her 453 equilibrium expected profit $\left(E \pi_{s}^{*}\right)$ increases with a constant variance $\left(\operatorname{var} \pi_{s}^{*}\right)$.

454 Proposition 5 demonstrates that the asymmetric reliance of the manufacturer and the supplier on the 455 bilateral channel leads to different "wins" for them when DPI increases (i.e., $k$ increases). As expected, 456 both the manufacturer and the supplier achieve higher expected profits. However, the changes in the risks of their profits are quite different. As the bilateral-channel productivity improvement increases, 458 the more powerful player, the supplier (the first mover in the bilateral contract negotiation), does not 459 bear any additional risk, but the less powerful player, the manufacturer (the second mover), bears a 460 higher risk. The reason is intuitive. The supplier can take the advantage of the less elastic demand from 461 the bilateral channel to charge a higher wholesale price while keep her total output volume unchanged 462 and, thus, she can avoid any additional risk. However, in response to the higher DPI in the bilateral 463 channel, the manufacturer needs to procure less from the futures market and expand his total output 464 volume and, thus, bears more risk facing uncertain final market demand. Our result is consistent with 465 the imbalanced power structure explanation for the inequity in B2B relationship-based collaborations 466 furnished by Collins and Burt (1999), Allen (2001), and Hingley (2005). In particular, Collins and Burt 467 (1999) and Allen (2001) demonstrate that the more or less powerful members in food supply chains 
468 bear different levels of risks.

\section{6. CONCLUDING REMARKS}

470 Based on the assumption that direct interactions through the simple wholesale price contract in the

471 bilateral channel may improve productivity for supply chain partners, we consider a two-echelon

472 supply chain with an upstream supplier and a downstream manufacturer both engaging in dual channel

473 (i.e., the bilateral channel and the futures market) transactions. In this paper, we first build a three-stage

474 game to analyze the strategic interactions between the supplier and the manufacturer, then we derive a

475 unique subgame perfect equilibrium in closed-form for the game. Finally, we discuss managerial

476 implications obtained from comparative statics analysis. Our major findings are summarized below.

477 The first finding establishes DPI as a necessary and sufficient condition to trigger and maintain

478 the bilateral contracting relation between the two supply chain partners. This result furnishes an

479 alternative productivity explanation for positive contract transactions on top of the strategic price

480 impact of the spot market trading in Mendelson and Tunca (2007) and the strategic threats under

481 trigger strategies in a repeated game setting in Taylor and Plambeck (2007a, 2007b).

482 The second finding reveals that the prior commitments to futures market trading allow the

483 equilibrium trading quantity and wholesale price in the bilateral channel to be independent of the

484 downstream market size and the upstream unit cost (Proposition 1). Compared to the case without the

485 futures market, this result demonstrates that the futures market trading effectively buffers the impact of

486 any change in the downstream market demand and upstream unit cost on the bilateral contracting

487 relation. This independence result implies that prior commitments in the futures market help mitigate

488 the double marginalization problem. 
The third finding demonstrates that an increase in the futures price increases the supplier's 490 expected profit and her associated risk, but it decreases the manufacturer's expected profit and his 491 associated risk. Therefore, the observed futures price can work as a valid indicator for supply chain 492 managers to forecast the change of bilateral contracting relations and corresponding performance 493 outcomes.

494 The fourth finding indicates that an increase in DPI of the bilateral channel makes the 495 manufacturer shift more of his procurement from the futures market to the bilateral channel. As a result, 496 the manufacturer would have a higher expected profit together with a higher risk, while the supplier is 497 able to seize a higher expected profit without incurring any additional risk.

498 There exist a few directions to extend this research. For instance, our model here essentially takes 499 a static view towards futures market movement. Once a futures price $F$ is observed, it remains constant 500 during the wholesale price contract negotiation. It is worthwhile to introduce a dynamic framework to 501 examine how futures price evolution affects supply chain operations, especially when the wholesale 502 price contract is subject to renegotiation. Another direction is to incorporate information asymmetry 503 regarding supply chain members' futures market trading activities.

\section{Acknowledgments:}

506 The authors would like to acknowledge the financial support from the Natural Sciences Foundation 507 (NSF) of China (Grant \#: 71272129 and 71572040), the Sichuan Science and Technology Foundation 508 for Young Researchers (Grant \# 2013JQ0031), and the Natural Sciences and Engineering Research 509 Council of Canada (NSERC) under its Discovery Grant program. 


\section{REFERENCES}

512 [1] Adcock, G. 2006. Taking the positives. European Supply Chain Management, March 11, 2006.

513 [2] Allen, S. 2001. Changes in supply chain structure: The impact of expanding consumer choice. In J.

514 F. Eastham, L. Sharples, \& S. D. Ball (Eds.), Food supply chain management: Issues for the 515 hospitality and retail sectors. Oxford: Butterworth-Heinemann.

516 [3] Bargawi, H., Newman, S., 2017. From futures markets to the farm-gate: a study of price formation 517 along Tanzania’s coffee commodity chain. Economic Geography, 93(2): 162-184.

518 [4] Cramer, J.S., Hartog, J., Jonker, N., van Praag, C.M., 2002. Low risk aversion encourages the 519 choice for entrepreneurship: an empirical test of a truism. Journal of Economic Behavior \& $520 \quad$ Organization, 48 (1): 29-36.

521 [5] Cohen, M., Agrawal, N. 1999. An analytical comparison of long and short term contracts. IIE $522 \quad$ transactions, 31(8): 783-796.

523 [6] Collins, A., Burt, S. 1999. Dependency in manufacturer-retailer relationships: The potential 524 implications of retail internationalization for indigenous food manufacturers. Journal of Marketing $525 \quad$ Management, 15(1), 673-693.

526 [7] Cucculelli, M., Ermini, B., 2013. Risk attitude, product innovation, and firm growth. Evidence 527 from Italian manufacturing firms. Economics Letters, 118 (2): 275-279.

528 [8] Dearing, B. 1990. The strategic benefits of EDI. Journal of Business Strategy, 11(1): 4-6.

529 [9] Dong, L., Liu, H. 2007. Equilibrium forward contracts on nonstorable commodities in the presence 530 of market power. Operations Research, 55(1): 128-145.

531 [10] Grey, W., Olvason, T., Shi, D. 2005. The role of e-marketplaces in relationship-based supply 
chains: A survey, IBM Systems Journal, 44(1): 109-123.

533 [11] Haksöz, Ç., Seshadri, S. 2007. Supply chain operations in the presence of a spot market: A review $534 \quad$ with discussion. Journal of Operational Research Society, 58(11): 1412-1429.

535 [12] Haksöz, Ç., Seshadri, S. 2011.Integrated production and risk hedging with financial instruments P.

536 Kouvelis, L. Dong, O. Boyabatli, R. Li (Eds.), The handbook of integrated risk management in global supply chains, 537 John Wiley \& Sons, Inc., Hoboken, NJ, USA (2011), 157-196.

538 [13] Hingley, M. K. 2005. Power to all our friends? Living with imbalance in supplier-retailer 539 relationships. Industrial Marketing Management, 34(8): 848 - 858.

540 [14] Kirkwood, C. W. 2004. Approximating risk aversion in decision analysis applications, Decision $541 \quad$ Analysis, 1(1): 51-67.

542 [15] Kleindorfer, P. R., Wu, D. 2003. Integrating long- and short-term contracting via business-to 543 business exchanges for capital-intensive industries. Management Science, 49(11): 1597-1615.

544 [16] Laughlin, K. 2003. LMP system overview. PJM Interconnection, LLC, Valley Forge, PA.

545 [17] Lee, H., Whang, S. 2002. The impact of the secondary market on the supply chain. Management $546 \quad$ Science, 48(6): 719-731.

547 [18] Levi, M., Kleindorfer, P.R., Wu, D.J. 2003. Codifiability, relationship-specific information 548 technology investment, and optimal contracting. Journal of Management Information Systems, $549 \quad 20(2): 77-98$.

550 [19] Mas-Colell, A., Whinston, M. D., JR Green, J. R. 1995. Microeconomic Theory. New York: $551 \quad$ Oxford University Press.

552 [20] Mendelson, H., Tunca, T. I. 2007. Strategic spot trading in supply chains. Management Science, 
554 [21] Newman, S. 2009. The new price makers: An investigation into the impact of financial investment 555 on coffee price behavior. NCCR-Trade Working Paper no 2009/7.

556 [22] Nyaga, G. N., Whipple, J. M., Lynch, D. F. 2010. Examining supply chain relationships: Do buyer 557 and supplier perspectives on collaborative relationship differ? Journal of Operations Management, $558 \quad 28(2): 101-114$

559 [23] Starbucks. 2010. Fiscal Year 2010 Annual Report. available at 560 http://www.sec.gov/Archives/edgar/data/829224/000119312510266333/d10k.htm, last accessed on $561 \quad$ March 14, 2017.

562 [24] Taylor, T. A., Plambeck, E. L. 2007a. Simple relational contracts to motivate capacity investment: 563 Price only vs. price and quantity. Manufacturing and Service Operations Management, 9(1): 94-113. 564 [25] Taylor, T. A., Plambeck, E. L. 2007b. Supply chain relationship and contracts: The impact of 565 repeated interaction on capacity investment and procurement. Management Science, 53(10): $566 \quad 1577-1593$.

567 [26] Tunca, T. I., Zenios, S. A. 2006. Supply auctions and relational contracts for procurement. 568 Manufacturing and Service Operations Management, 8(1): 43-67.

569 [27] Ulrich, D., Barney, J. B. 1984. Perspectives in organizations: Resource dependence, Efficiency, $570 \quad$ and populations. Academy of Management Review, 9(3): 471-481.

571 [28] Willebrands, D., Lammers, J., Hartog, J., 2012. A successful businessman is not a gambler. Risk 572 attitude and business performance among small enterprises in Nigeria. Journal of Economic 573 Psychology 33 (2): 342-354. 
574 [29] Zabel, E. Monopoly and uncertainty, Review of Economic Studies, 1970, 37(2): 205-219.

575

576

577

578

579

580

581

582

583

584

$585 w^{*}$ and $q_{s}^{*}$.

586

587 Proposition 1 is continuous and strictly increases in $B$ with $q_{s f}^{*} \rightarrow-\infty$ as $B \rightarrow 0$ and 588 590 then $q_{m f}^{*} \geq 0$ is equivalent to

Substituting (A1) into (12), we have

$$
\begin{aligned}
0= & \left(\frac{1}{2 k}-\frac{\left(k^{2} B+A\right)\left(3 k^{2} B+A\right)}{k^{3} B A}\right) q_{m f}+\left(\frac{-1}{2 k B}+\frac{\left(k^{2} B+A\right)\left(3 k^{2} B+A\right)}{k^{3} B^{2} A}\right) a \\
& +\left(\frac{2 k^{2} B+A}{2 k^{2} B A}-\frac{\left(2 k^{2} B+A\right)^{2}}{k^{3} B^{2} A}\right) F \\
= & \frac{\left(2 k^{2} B+A\right)\left[\left(3 k^{2} B+2 A\right) a+\left(k B-4 k^{2} B-2 A\right) F-B\left(3 k^{2} B+2 A\right) q_{m f}\right]}{2 k^{3} B^{2} A}
\end{aligned}
$$

Then we have

$$
q_{m f}^{*}=\frac{a}{B}+\frac{\left(k B-4 k^{2} B-2 A\right) F}{B\left(3 k^{2} B+2 A\right)}=\frac{a}{B}+\left(\frac{k-k^{2}}{3 k^{2} B+2 A}-\frac{1}{B}\right) F=\frac{a-F}{B}+\frac{k(1-k) F}{3 k^{2} B+2 A}
$$

Substituting $q_{m f}^{*}$ into (12), (6) and (5), it is easy to verify the other equilibrium variables $q_{s f}^{*}$, Second, we explore conditions to ensure $q_{s f}^{*}$ and $q_{m f}^{*}$ to be non-negative. Since $q_{s f}^{*}$ given in $q_{s f}^{*} \rightarrow\left(F-c_{0}\right) / A>0$ as $B \rightarrow+\infty$, thus there exists a critical $B^{\#}$ such that $q_{s f}^{*} \geq 0$ for all $B \geq B^{\#}$. Furthermore, since $q_{m f}^{*}$ given in Proposition 1 is continuous and strictly increases in $a$, 


$$
a \geq\left[1+\frac{k(k-1) B}{3 k^{2} B+2 A}\right] F \equiv a^{\#}(B)
$$

Finally, $w^{*}$ and $q_{s}^{*}$ are clearly non-negative. Proposition 1 is thus proved.

604

\section{Proof of Proposition 2.}

For $k>1$, we first calculate $\partial w^{*} / \partial F, \partial q_{s}^{*} / \partial F$ and $\partial q_{m f}^{*} / \partial F$ as follows:

$$
\begin{gathered}
\frac{\partial w^{*}}{\partial F}=\frac{k^{2} B(1+2 k)+A(1+k)}{3 k^{2} B+2 A}>\frac{k^{2} B(1+2)+A(1+1)}{3 k^{2} B+2 A}=1 \\
\frac{\partial q_{s}^{*}}{\partial F}=\frac{(k-1)\left(2 k^{2} B+A\right)}{k^{2} B\left(3 k^{2} B+2 A\right)}>0, \frac{\partial q_{m f}^{*}}{\partial F}=\frac{-1}{B}+\frac{k(1-k)}{3 k^{2} B+2 A}<0
\end{gathered}
$$

Note that $q_{s f}^{*} \geq 0$ and $c_{0}>0$ implies

$$
\frac{F-c_{0}}{A}-\frac{k-1}{k^{2}} \frac{\left(2 k^{2} B+A\right) F}{B\left(3 k^{2} B+2 A\right)} \geq 0 \Rightarrow \frac{1}{A}-\frac{k-1}{k^{2}} \frac{\left(2 k^{2} B+A\right)}{B\left(3 k^{2} B+2 A\right)}>0
$$

We thus have

$$
\frac{\partial q_{s f}^{*}}{\partial F}=\frac{1}{A}-\frac{k-1}{k^{2}} \frac{\left(2 k^{2} B+A\right)}{B\left(3 k^{2} B+2 A\right)}>0
$$

\section{Proof of Proposition 3.}

For the first part, with the equilibrium variables given in Proposition 1, we have

$$
\begin{aligned}
\frac{\partial E \pi_{m}}{\partial F}= & {\left[a-2 b\left(k q_{s}^{*}+q_{m f}^{*}\right)\right] \frac{\partial\left(k q_{s}^{*}+q_{m f}^{*}\right)}{\partial F}-q_{s}^{*} \frac{\partial w^{*}}{\partial F}-w^{*} \frac{\partial q_{s}^{*}}{\partial F}-F \frac{\partial q_{m f}^{*}}{\partial F}-q_{m f}^{*} } \\
= & \rho_{m} \sigma_{\varepsilon}^{2} \frac{\partial\left(k q_{s}^{*}+q_{m f}^{*}\right)}{\partial F}+\frac{F}{B} \times\left(\frac{k-1}{k}\right)^{2} \times \frac{3 k^{2} B+A}{3 k^{2} B+2 A} \times \frac{k^{2} B+A}{3 k^{2} B+2 A}-\frac{a-F}{B} \\
& <\rho_{m} \sigma_{\varepsilon}^{2} \frac{\partial\left(k q_{s}^{*}+q_{m f}^{*}\right)}{\partial F}+\frac{F}{B}\left[\left(\frac{k-1}{k}\right)^{2} \times \frac{3 k^{2} B+A}{3 k^{2} B+2 A} \times \frac{k^{2} B+A}{3 k^{2} B+2 A}-\frac{1}{3}\right] \\
& <\rho_{m} \sigma_{\varepsilon}^{2} \frac{\partial\left(k q_{s}^{*}+q_{m f}^{*}\right)}{\partial F}
\end{aligned}
$$

605 where the first inequality follows from $q_{m f}^{*} \geq 0$ when $k \rightarrow \infty$, the second inequality is derived from 
606

607

608

609

610

611

612

613

614

615

616

617

618

619

620

the fact that $(k-1)^{2} / k^{2}<1$ and $\left(3 k^{2} B+A\right)\left(k^{2} B+A\right) /\left(3 k^{2} B+2 A\right)^{2}<1 / 3$.

Moreover, (5) implies

$$
\frac{\partial\left(k q_{s}^{*}+q_{m f}^{*}\right)}{\partial F}=-\frac{1}{B k} \frac{\partial w^{*}}{\partial F}<0
$$

Therefore, we have $\partial E \pi_{m} / \partial F<0$. Further, with (A2) and $\operatorname{var} \pi_{m}=\sigma_{\varepsilon}^{2}\left(k q_{s}+q_{m f}\right)^{2}$, it implies

$$
\frac{\partial \operatorname{var} \pi_{m}}{\partial F}=2 \sigma_{\varepsilon}^{2}\left(k q_{s}^{*}+q_{m f}^{*}\right) \frac{\partial\left(k q_{s}^{*}+q_{m f}^{*}\right)}{\partial F}<0
$$

For the second part, $\partial E \pi_{s} / \partial F$ is calculated as

$$
\begin{aligned}
\frac{\partial E \pi_{s}}{\partial F} & =\left(F-c_{0}\right) \frac{\partial q_{s f}^{*}}{\partial F}+q_{s f}^{*}+\left(w^{*}-c_{0}\right) \frac{\partial q_{s}^{*}}{\partial F}+\frac{\partial w^{*}}{\partial F} q_{s}^{*} \\
& =\left(F-c_{0}\right)\left(\frac{\partial q_{s f}^{*}}{\partial F}+\frac{\partial q_{s}^{*}}{\partial F}\right)+\left(w^{*}-F\right) \frac{\partial q_{s}^{*}}{\partial F}+q_{s f}^{*}+\frac{\partial w^{*}}{\partial F} q_{s}^{*} \\
& =\left(F-c_{0}\right) \frac{1}{A}+\left(w^{*}-F\right) \frac{\partial q_{s}^{*}}{\partial F}+q_{s f}^{*}+\frac{\partial w^{*}}{\partial F} q_{s}^{*}>0
\end{aligned}
$$

where the inequality is due to $w^{*}>F>c_{0}, \partial q_{s}^{*} / \partial F>0$, and $\partial w^{*} / \partial F>0$.

Finally, we have

$$
\frac{\partial \operatorname{var} \pi_{s}}{\partial F}=2 \sigma_{c}^{2}\left(q_{s}^{*}+q_{s f}^{*}\right) \frac{\partial\left(q_{s}^{*}+q_{s f}^{*}\right)}{\partial F}=2 \sigma_{c}^{2}\left(q_{s}^{*}+q_{s f}^{*}\right)\left(\frac{\partial q_{s f}^{*}}{\partial F}+\frac{\partial q_{s}^{*}}{\partial F}\right)=\frac{2 \sigma_{c}^{2}\left(q_{s}^{*}+q_{s f}^{*}\right)}{A}>0
$$

\section{Proof of Proposition 4.}

Firstly, $\partial q_{m f}^{*} / \partial k, \partial w^{*} / \partial k$ and $\partial Q_{m} / \partial k$ are derived as

$$
\begin{gathered}
\frac{\partial q_{m f}^{*}}{\partial k}=\frac{\left[-3 k^{2} B+2 A(1-2 k)\right] F}{\left(3 k^{2} B+2 A\right)^{2}}<0, \frac{\partial w^{*}}{\partial k}=\frac{\left[6 k^{4} B^{2}+k A B(9 k-2)+2 A^{2}\right] F}{\left(3 k^{2} B+2 A\right)^{2}}>0 \\
\frac{\partial q_{m}}{\partial k}=\frac{\left[6 k^{4} B^{3}+\left(2 k^{3}+5 k^{2}\right) A B^{2}+2 A^{2} B\right] F}{\left[k B\left(3 k^{2} B+2 A\right)\right]^{2}}>0
\end{gathered}
$$

Secondly, $\partial Q_{s} / \partial k=0$ follows from $Q_{s}=q_{s f}^{*}+q_{s}^{*}=\left(F-c_{0}\right) / A$ (see Proposition 1). 
Thirdly, from Proposition 1, we have

$$
\frac{\partial W_{m}}{\partial k}=\frac{\left(-3 B^{2} k^{4}+2 A B k^{3}-7 A B k^{2}-2 A^{2}\right) F}{\left[k\left(3 k^{2} B+2 A\right)\right]^{2}}
$$

Let $g(k)=-3 B^{2} k^{4}+2 A B k^{3}-7 A B k^{2}-2 A^{2}$. Then we have $g(1)=-3 B^{2}-5 A B-2 A^{2}<0$ and $g^{\prime}(k)=-12 B^{2} k^{3}+6 A B k^{2}-14 A B k$. Clearly, $g^{\prime}(1)=-12 B^{2}-8 A B<0$. To show that $g^{\prime}(k)<0$ for all $k>1$, we need only to show that $g^{\prime}(k)=0$ has no real solution on $(1,+\infty)$. Assume that there exists a solution to $g^{\prime}(k)=0$ on $(1,+\infty)$. We must have $A \geq 56 B / 3$. However, from Proposition 1 , since $(k-1) / k^{2}<1 / 4$ and $\left(2 k^{2} B+A\right) /\left(3 k^{2} B+2 A\right)<2 / 3$ for all $k>1$, then $q_{s f}^{*} \geq 0$ for all $k>1$ and $c_{0}>0$ implies $6 B \geq A$. We thus have $56 B / 3 \geq 28 A / 9>A$, leading to a contradiction.

$$
\text { Finally, (5) implies that }
$$

\section{Proof of Proposition 5.}

$$
\frac{\partial Q_{m}}{\partial k}=\frac{\partial\left(k q_{s}^{*}+q_{m f}^{*}\right)}{\partial k}=-\frac{1}{B} \times \frac{\partial W_{m}}{\partial k}>0 .
$$

For the first part, with the equilibrium solution given in Proposition 1, we have

$$
\begin{aligned}
\frac{\partial E \pi_{m}}{\partial k} & =\left[a-2 b\left(k q_{s}^{*}+q_{m f}^{*}\right)\right] \frac{\partial\left(k q_{s}^{*}+q_{m f}^{*}\right)}{\partial k}-q_{s}^{*} \frac{\partial w^{*}}{\partial k}-w^{*} \frac{\partial q_{s}^{*}}{\partial k}-F \frac{\partial q_{m f}^{*}}{\partial k} \\
& =\left[\frac{w^{*}}{k}+\rho_{m} \sigma_{\varepsilon}^{2}\left(k q_{s}^{*}+q_{m f}^{*}\right)\right] \frac{\partial\left(k q_{s}^{*}+q_{m f}^{*}\right)}{\partial k}-q_{s}^{*} \frac{\partial w^{*}}{\partial k}-w^{*} \frac{\partial q_{s}^{*}}{\partial k}-F \frac{\partial q_{m f}^{*}}{\partial k} \\
& =\rho_{m} \sigma_{\varepsilon}^{2}\left(k q_{s}^{*}+q_{m f}^{*}\right) \frac{\partial\left(k q_{s}^{*}+q_{m f}^{*}\right)}{\partial k}+\left(\frac{w^{*}}{k}-F\right) \frac{\partial q_{m f}^{*}}{\partial k}-k q_{s}^{*} \frac{\partial W_{m}}{\partial k}
\end{aligned}
$$

634 where the second equality is due to (5).

635 Then $\partial \operatorname{var} \pi_{m} / \partial k$ is computed as

$$
\frac{\partial \operatorname{var} \pi_{m}}{\partial k}=2 \rho_{m} \sigma_{\varepsilon}^{2}\left(k q_{s}^{*}+q_{m f}^{*}\right) \frac{\partial\left(k q_{s}^{*}+q_{m f}^{*}\right)}{\partial k}
$$



have $\partial \operatorname{var} \pi_{m} / \partial k>0$. Furthermore, the first and third terms in the last equality of (A3) are positive,

and the second term is also positive, since for all $k>1$, we have $\partial q_{m f}^{*} / \partial k<0$ and

$$
\frac{w^{*}}{k}-F=\frac{(1-k)\left(k^{2} B+A\right) F}{k\left(3 k^{2} B+2 A\right)}<0
$$

For the second part, we can directly calculate $\partial E \pi_{s} / \partial k$ as

$$
\frac{\partial E \pi_{s}}{\partial k}=w^{*} \frac{\partial q_{s}^{*}}{\partial k}+q_{s}^{*} \frac{\partial w^{*}}{\partial k}+F \frac{\partial q_{s f}^{*}}{\partial k}-c_{0} \frac{\partial\left(q_{s}^{*}+q_{s f}^{*}\right)}{\partial k}=\left(w^{*}-F\right) \frac{\partial q_{s}^{*}}{\partial k}+q_{s}^{*} \frac{\partial w^{*}}{\partial k}
$$

where the last equality is derived from the fact that $\partial Q_{s} / \partial k=\partial\left(q_{s}^{*}+q_{s f}^{*}\right) / \partial k=0$ (see Proposition 4). Further,

$$
\frac{\partial q_{s}^{*}}{\partial k}=\frac{k B\left[-6 k^{5} B^{2}+12 k^{4} B^{2}-5 k^{3} A B+12 k^{2} A B-2 k A^{2}+4 A^{2}\right] F}{\left[k^{2} B\left(3 k^{2} B+2 A\right)\right]^{2}}
$$

Substituting (A6) and $\partial w^{*} / \partial k$ in Proposition 4 into (A5), we have

$$
\frac{\partial E \pi_{s}}{\partial k}=\frac{\left.2(k-1)\left(2 k^{2} B+A\right)\right)\left[6 k^{5} B^{3}+k^{3}(2 k+5) A B^{2}+2 k A^{2} B\right] F^{2}}{\left(k^{2} B\right)^{2}\left(3 k^{2} B+2 A\right)^{3}}>0
$$

Finally, $\partial \operatorname{var} \pi_{s} / \partial k=0$ follows from the fact that $\partial Q_{s} / \partial k=\partial\left(q_{s}^{*}+q_{s f}^{*}\right) / \partial k=0$.

\section{Appendix B: The robustness of Propositions 1-5 to a setting of different futures prices}

In this appendix, we show that the results obtained with the assumption that the manufacturer (the supplier) buys (sells) at a same futures price are robust to the setting with different futures prices. Assume that the supplier sells at $F+\Delta F$ with $\Delta F \in(-F,(k-1) F)$ while the manufacturer buys at $F$ where $\Delta F>-F$ simply implies that the supplier sells at a positive futures price and $\Delta F<(k-1) F$ ensures the possibility for the supplier and the manufacturer to trade via the bilateral channel (It will be more profitable for the supplier to sell all of its product to the futures market if it observes a futures price larger than $k F$, which is the highest wholesale price that the manufacturer can 
657

658

660 where “*” represents the "equilibrium” solutions in Proposition 1.

661 Clearly, these equilibrium solutions are continuous in $\Delta F$. This in turn implies that the 662 continuity of the equilibrium expected profits and their variances in $\Delta F$. With this continuity, one can 663 easily check that all the partial derivatives in the comparative statics analyses in Section 5 are 664 continuous in $\Delta F$. Thus, there must exist a neighborhood $(-\overline{\Delta F}, \overline{\Delta F})$ of $\Delta F=0(\overline{\Delta F}>0)$ such that 665 for all $\Delta F \in(-\overline{\Delta F}, \overline{\Delta F})$, the signs of all our partial derivatives keep unchanged. Therefore, our results 666 can be applied to situations where the futures-price differences are not too large (i.e. $667 \Delta F \in(-\overline{\Delta F}, \overline{\Delta F}))$. 